Print ISSN: 2233-4165 / Online ISSN: 2233-5382

doi:http://dx.doi.org/10.13106/ijidb.2018.vol9.no7.71.

\title{
The Interactive Effects of Motivation and Contingent Rewards on Employee Creativity*
}

\section{조직구성원의 외재적, 내재적 동기와 창의성의 관계: 조건적 보상의 조절효과}

\author{
Soyeon Hwang(황소연) ${ }^{* *}$, Heajung Jung(정혜정) ${ }^{* * *}$
}

Received: June 15, 2018. Revised: July 5, 2018. Accepted: July 15, 2018.

\begin{abstract}
Purpose - This study examined the effects of intrinsic and extrinsic motivation on employee creativity. Past research has consistently shown that intrinsic motivation is positively related to creativity. Yet conflicting results have been reported about the relationship between extrinsic motivation and creativity. To explore the reason why extrinsic motivation can either help or hurt creativity, we examined the role of contingent rewards as a moderator and tested whether either tangible or intangible rewards contingent upon creative performance significantly impact the relationship between extrinsic motivation and creativity. Research design, data, and methodology - Survey data was collected from employees working for diverse organizations in Korea through online research firm. Only employees who reported their job or organization provided opportunities to use their creativity were allowed to continue the survey. Out of 305 initial responses collected, those with too much missing data were deleted, which finally left 278 responses for statistical analyses. To examine the validity of the measurements, confirmatory factor analysis was first conducted. Next, to test the hypothesized relationships, multiple hierarchical regression analyses were conducted.

Results - As hypothesized, both intrinsic and extrinsic motivation had positive effects on creativity. It was shown that contingent rewards did not influence the positive relationship between intrinsic motivation and creativity, but did significantly moderate the relationship between extrinsic motivation and creativity in a way that tangible rewards strengthened the relationship while intangible rewards mitigated the same relationship.

Conclusions - This research enhances our understanding on the relationship between motivation type, rewards, and creativity. Intrinsically motivated employees showed a high level of creativity regardless of whether rewards were expected or not. In contrast, extrinsically motivated employees showed more or less creative behavior depending on whether they were expected to have tangible or intangible rewards. As extrinsic motivation is typically associated with tangible rewards such as pay, promotion, etc., tangible rewards were seen to be more effective in promoting creative performance from extrinsically motivated employees than intangible rewards. Our findings make a significant theoretical contribution to reconcile prior inconsistent findings. Furthermore, they provide useful insights for managers and organizations into developing effective strategies for facilitating employee creativity.
\end{abstract}

Keywords: Intrinsic Motivation, Extrinsic Motivation, Contingent Reward, Creativity.

JEL Classifications: C12, C42, J20, M54.

\section{1. 서론}

현대 사회의 급변하는 경영 환경에서 창의성과 혁신은 더 이상 특정 산업이나 기업에만 필요한 요소가 아니라 한 기업 의 생존과 성공을 결정하는 핵심요소로 여겨지고 있다. 이는

* This paper was modified and developed from the thesis of the first author.

** First Author, School of Business, Konkuk University, Korea.

*** Corresponding Author, Assistant professor, School of Business, Konkuk University, Korea.

Tel: +82-2-450-3634, E-mail: heajung@konkuk.ac.kr
창의성이 단순히 새로운 아이디어나 제품을 만들어 내는 것뿐 아니라 변화하는 환경에 대한 적응과 문제해결 등 조직의 긍 정적인 변화에 기여하기 때문이다. 따라서 창의성은 혁신을 필 요로 하는 조직의 구성원이 갖추어야 할 중요한 자질로 인식 되기도 한다(Zhou \& George, 2001; Yang, Cho, Kim, Eom, Kim, \& Youn, 2015).

창의성과 혁신을 설명하는 가장 중요한 이론 중 하나인 요 소이론(componential theory: Amabile, 1997)은 개인의 창의성 을 구성하는 주요 요소로 전문성(expertise), 창의적 사고능력 (creative-thinking skill), 내재적 동기(intrinsic motivation) 세 가 지를 꼽았다. 이와 같이 개인의 창의성을 발휘하는 데에는 동기 
가 중요한 역할을 한다. 동기는 크게 일 자체에서 흥미와 의미 를 느껴 열심히 일을 하고자 하는 내재적 동기(intrinsic motivation)와 외적으로 주어지는 다양한 형태의 보상에 의해 유 인되는 외재적 동기(extrinsic motivation)로 분류된다(Cerasoli, Nicklin, \& Ford, 2014). 이제까지 많은 연구자들이 내재적 동기 와 외재적 동기가 창의성에 미치는 영향을 탐색하였으나(e.g., Grant \& Berry, 2011; Zhang \& Bartol, 2010; Byron \& Khazanchi, 2012), 내재적 동기와 외재적 동기의 역할과 역동적 관계에 대한 연구는 여전히 진행 중이다.

우선, 초기의 연구들은 요소이론(Amabile, 1997)에서도 강조 되고 있듯이 탐색이나 도전과 같은 외적 강화(reinforcement)에 기인하지 않은 자발적 행동들을 설명하기 위해 외재적 동기보 다는 내재적 동기에 더 많은 관심을 보여왔다(Amabile et al., 1996). 대부분의 연구결과들이 내재적 동기가 창의성에 긍정 적인 영향을 미치는 것을 일관되게 보여주었으나 일부 학자들 은 내재적 동기와 성과와의 관계에 있어서 외적 보상의 약화 효과(undermining effect)가 존재한다고 보고하였다(Cameron, Banko, \& Pierce, 2001; Deci, Koestner, \& Ryan, 2001). 즉, 내재적 동기에 따라 그 자체가 즐거워서 하던 일에 외적인 보 상이 주어지면 그 일을 하는 원래의 즐거움이 보상에 의해 일 한다는 인식으로 전환되어 오히려 동기가 저하되고 성과가 줄 어든다는 것이다.

내재적 동기에 대한 연구에 비해 외재적 동기가 창의성에 미치는 영향에 관한 연구는 상대적으로 적다. 기존의 연구들은 주로 외적 보상이 외재적 동기를 유발하여 결과변수에 영향을 미친다고 보고 외재적 동기(extrinsic motivation) 대신 외적 보 상(extrinsic reward)의 유무를 변수로 살펴보았다(Cerasoli et al., 2014; Deci et al., 2001; George \& Zhou, 2002; Hendijani, Bischak, Arvani, \& Dugar, 2016). 하지만 외재적 동기가 한 개 인이 외적 보상에 의해 동기부여 되는 정도를 나타내는 개인의 특성변수라면, 외적 보상은 약속된 성과에 대한 조건적 보상을 조직이 제공하는 지의 여부를 나타내는 상황 변수이다. 즉, 외 적 보상이 존재한다는 것 자체와 개인이 그 보상에 이끌리는 것은 별개이다. 따라서 이 둘을 분리하여 볼 필요가 있다.

또한, 외재적 동기에 관한 기존 연구들은 상반된 결과를 보 이기도 한다. 외재적 동기가 창의성을 향상시킬 수 있음을 보 여준 연구도 있고(Guay, Vallerand, \& Blanchard, 2000; Kasof, Chen, Himsel, \& Greenberger, 2007), 오히려 창의성을 저해 하는 결과를 보고한 연구들도 있다(Cooper \& Jayatilaka, 2006; Gagné \& Deci, 2005). 이렇듯 외재적 동기가 창의성에 미치는 영향이 일관되지 않게 나타나는 원인 중 하나로 기대 하는 보상의 유형을 생각해볼 수 있다. 가령, 외재적 동기가 높은 개인이라 하더라도 원하는 보상이 유형의 보상인지 무형 의 보상인지에 따라 보상에 따른 동기수준이 달라질 수 있다. 다시 말해, 개인이 원하는 보상과 주어지는 보상이 서로 "매치 (match)"되어야 가장 높은 수준의 창의성을 발휘할 수 있는 것 이다(Shalley \& Gilson, 2004). 따라서 조건적 보상의 유형이 동기와 창의성의 관계를 결정하는 변수로 작용할 가능성이 있 으므로 그에 대한 실증연구가 필요하다고 본다.

창의성에 대한 상호작용 관점(interactionist perspective: Woodman, Sawyer, \& Griffin, 1993)을 강조하는 학자들은 창 의성을 조직 내 다양한 수준에서 나타나는 개인과 상황 간의 복합적인 상호작용이라고 기술한다. 즉, 개인의 창의성은 성격 (개방성: George \& Zhou, 2001, 주도적 성격: Gong, Cheung, Wang, \& Huang, 2012), 인지 스타일(cognitive style; Tierney,
Farmer, \& Graen, 1999), 목표지향성(goal orientation: Janssen \& Van Yperen, 2004)과 같은 개인의 특성과 보상 (rewards), 물리적 환경(physical environment)과 같은 상황적 변수가 복합적으로 작용한 결과로 나타난다는 것이다. 본 연구 의 목적은 개인특성으로서 외재적 동기와 내재적 동기가 창의 성에 미치는 영향을 함께 살펴보고, 상황변수로 볼 수 있는 유 형 혹은 무형의 조건적 보상이 동기와 창의성의 관계에 어떠 한 영향을 미치는지 실증적으로 탐색하는데 있다.

\section{2. 선행연구 고찰}

\section{1. 창의성}

창의성은 제품이나, 서비스, 업무과정, 절차에 관하여 새롭 고(novel) 유용한(useful) 아이디어를 생산해내는 것이다 (Amabile, 1997; Oldham \& Cummings, 1996). 여기서 새로운 아이디어는 조직 내 기존의 아이디어에 비해 독특(unique)하다 고 여겨지는 아이디어를 말하고, 유용한 아이디어는 조직에 단 기적 혹은 장기적으로 간접적 혹은 직접적인 가치를 부여할 수 있는 아이디어를 의미한다(Shalley \& Gilson, 2004).

창의성을 판단할 대상은 두 가지로 구분될 수 있다. Shalley and Perry-Smith (2001)는 '산물'에 집중하여 창의성에 대한 정 의를 내렸다. 이들은 창의성을 새롭고 유용한 아이디어나 문제 해결 방법 혹은 독창적이고 유용한 과정을 통해 얻은 결과물이 라 정의하였다. 반면, Dewett(2007)은 창의성을 정의하는 데 있 어 '과정'이나 '원인'에 초점을 맞추었다. 이들은 창의성을 일과 관련된 생각, 혹은 그러한 생각을 만들어 내는 과정이라 보았다. 이와 유사하게 Amabile (1988), Zhang and Bartol (2010), Grant and Berry (2011), Zhu, Gardner, and Chen (2018) 또한 창의성 을 독창적이고 실용적인 생각이나 행동이라고 정의내렸다.

이렇게 볼 때 창의성은 보다 광범위하고 포괄적인 속성으로 이해할 수 있다(Mumford \& Gustafson, 1988). 즉, 창의성은 단순히 새로운 아이디어를 생성하는 것뿐 아니라 새로운 방식 으로 문제를 해결하고 조직을 변화시키는 과정으로서 강조되 므로(Zhou \& George, 2001), 조직에서 구성원의 창의성은 제 품의 개발과 생산, 업무수행 프로세스, 각종 서비스 관련 업무, 제도운영 및 프로젝트 활동 등 다양한 장면에서 발현될 수 있 다. 따라서 창의적인 아이디어는 조직의 모든 수준과 모든 직 무에서 생성될 수 있다(Shalley \& Gilson, 2004).

창의성은 유사한 개념을 가진 혁신행동과 구분할 필요가 있 다. 창의성은 새롭고 유용한 아이디어의 산출을 의미한다면, 혁신행동은 새로운 아이디어를 구상하고 확산시키며 실천하는 행동을 말한다(Scott \& Bruce, 1994). 즉, 구성원들 간에 창의 적인 아이디어를 공유하고 이러한 아이디어들이 조직 혹은 집 단에서 성공적으로 시행되었을 때 비로소 혁신으로 간주된다 (Mumford \& Gustafson, 1988; Shalley \& Gilson, 2004). 따라 서 창의성은 혁신을 이루기 위한 첫 번째 단계로 볼 수 있다 (West \& Farr, 1990).

\section{2. 내재적 동기와 창의성의 관계}

자기결정이론(self-determination theory; Deci \& Ryan, 1985) 에 따르면, 개인의 동기는 자율성 혹은 자기결정 수준에 따라 구분되며 내재적 동기는 최고의 자기결정성을 갖는 동기유형 이다(Koestner, Losier, Vallerand, \& Carducci, 1996). 내재적 동 
기란 구성원이 과업수행의 결과로 얻게 되는 외적인 보상이 아 닌 과업자체를 수행하는 과정에서 얻게 되는 즐거움, 성취감, 도 전감 등에 의해 동기부여 되는 것으로 정의할 수 있다(Deci \& Ryan, 1985; Amabile, Hill, Hennessey, \& Tighe, 1994).

이러한 내재적 동기는 자기결정이론에서 제시하는 세 가지 심리적 욕구인 자율성(autonomy), 유능성(competence), 관계성 (relatedness) 욕구가 충족될수록 강화되며, 과업에 대한 중요 성과 의미를 지각하고 몰입하게 하여 일 자체에 대한 흥미와 문제에 대한 열정을 갖도록 이끈다(Amabile, 1988). 따라서 내 재적으로 동기부여가 된 구성원은 직무자체에서 오는 만족, 재 미 혹은 도전에 의해 직무를 수행한다(Aletraris, 2010; Ryan \& Deci, 2000).

내재적 동기가 창의성에 미치는 긍정적인 영향은 비교적 일 관되게 보고되고 있다(Dewett, 2007; Eisenberg \& Thompson, 2011). 직무특성인 자율성과 기술다양성, 개인특성인 성실성과 개방성, 그 외에도 내적 동기와 창의성에 영향을 줄 수 있는 심리적 안전감 등 다양한 변수들을 통제한 후에도 내재적 동 기는 창의성을 유의미하게 예측하는 것으로 보고되었다(Grant \& Berry, 2011). R\&D 연구원들을 대상으로 한 연구에서는 내 재적 동기가 창의성에 미치는 긍정적인 영향이 외재적 동기를 통제한 뒤에도 여전히 나타났다(Zhu et al., 2016). 뿐만 아니 라 내재적 동기는 심리적 임파워먼트(Lee \& Kim, 2016), 상사 신뢰(Kim, 2015) 등이 창의성에 미치는 영향을 설명하는 매개 변수로도 연구되어 왔다.

내재적 동기는 전반적으로 성과에 긍정적인 영향을 미치지 만, 특히 단순하고 양적인 과업보다는 복잡하고 질적인 과업에 있어서 보다 중요한 역할을 한다(Zhu, Gardner, \& Chen, 2016). 창의성을 요구하는 과제는 질적인 과업에 해당되며 보 다 복잡하고 다양한 기술을 필요하고(Rich, 2006), 높은 몰입 과 낮은 외적 통제를 요구하는 특징이 있다(Deci \& Ryan, 2000). 내재적 동기가 높은 개인은 과업 자체에 대한 강한 흥 미와 호기심을 경험하는 만큼 학습욕구의 증가로 강한 몰입과 지속적 노력을 보이게 된다(Shalley et al., 2004; Grant \& Berry, 2011). 또한 내재적 동기는 자율성의 경험을 촉진하여 인지적 유연성을 확대시키고 이를 통해 창의적인 아이디어를 만들어내 는데 도움이 된다(Shalley et al., 2004; Vansteenkiste, 2007). 이러한 이론과 기존 연구 결과를 바탕으로 다음과 같이 가설 을 수립하였다.

<가설 1> 내재적 동기는 창의성에 긍정적인 영향을 미칠 것이다.

\section{3. 외재적 동기와 창의성의 관계}

Amabile 등(1994)은 외재적 동기를 '보상이나 인정 또는 타 인의 지시 등 직무 자체와 별개의 요소에 대한 반응으로 일을 하려는 동기'로 정의하였다. Stajkovic and Luthans(2001)는 '경제적 이익, 사회적 인정, 긍정적인 평가 등에 수반되는 도구 적인(instrumental) 가치에 의해 생기는 동기'를 가리켜 외재적 동기라고 하였다. Deci and Ryan(1985)의 자기결정이론의 하 위이론 중 하나인 유기통합이론(organismic integration theory) 은 자기결정의 정도에 따라 외재적 동기를 외적 조절(external regulation), 내사 조절(introjected regulation), 동일시 조절 (identified regulation), 통합 조절(integrated regulation)의 네 가지 유형으로 분류하였다.

내재적 동기와 창의성에 관한 연구들은 대체적으로 일관된
결과를 보고한데 비해 외재적 동기에 관한 연구결과들은 상반 된 결과들이 혼재한다. 우선, 외재적 동기가 창의성을 오히려 저해한다고 보는 관점이 있다. 자기결정이론에 따르면 외재적 동기는 단순한 직무 수행은 향상시키지만 창의성이 요구되는 복잡한 직무 수행에는 오히려 방해가 될 수 있으며(Gagné \& Deci, 2005), 이는 보상에 의존하는 행동주의적 접근으로는 인 간의 창의력, 지구력, 몰입 등과 같은 심리적 자원에 대한 활 용을 극대화할 수 없다고 보는 견해와 일치한다. 또한 외재적 동기가 높은 사람은 이미 학습된 공통적이고 효과적인 업무처 리 방식에 익숙해져 있으므로 (Cooper \& Jayatilaka, 2006) 유 연한 사고방식을 요구하는 창의성이 덜 발현될 수 있다.

한편, 반대로 외재적 동기가 내재적 동기를 높일 수 있음을 보여준 연구들도 있다(Kasof et al., 2007). 즉, 외재적 동기가 창의성을 직접 향상시키지는 않지만 내재적 동기와의 상호작 용 하에 창의성과 같은 성과에 긍정적인 영향을 줄 수 있다는 주장이다. 가령, Eisenberger and Shanock(2003)은 창의성과 같은 특정한 유형의 성과에 따라 주어지는 외적 보상은 자율 성과 유능성에 대한 욕구를 만족시킬 수 있다고 하였다. 또, 외재적 동기가 직접적으로 창의성에 긍정적인 영향을 줄 수 있다는 주장도 있다. 내재적 동기와 외재적 동기의 다차원성에 대해 연구한 Guay et al.(2000)은 자신의 경력발전을 위해 일 을 하는 것은 외재적 동기에 의해 동기 부여된 것이지만 내재 적 동기와 마찬가지로 성과에 긍정적인 영향을 미친다고 주장 한다. 즉, 외적 목표와 규범으로 형성된 외재적 동기도 역시 순기능적인 역할을 할 수 있다는 것이다.

실제로 한국 보험회사를 대상으로 한 연구에서 외재적 동기 가 창의성에 미치는 긍정적인 영향이 제시되었고(Yoon et al., 2015), 대학생을 대상으로 한 종단연구에서도 외재적 동기는 창의적 의도(creativity intention)를 통해 창의적 성과에 긍정적 인 영향을 미치는 것으로 나타났다(Choi, 2004). 또 다른 연구 원들을 대상으로 한 연구에서는 외재적 동기는 창의성에 직접 적인 영향은 미치지 않았지만 내재적 동기와 창의성의 관계를 부적으로 조절하는 것으로 나타났다(Zhu, Gardner, \& Chen, 2016). 구체적으로 외재적 동기가 높으면 내재적 동기와 창의 성은 부정적인 관계를, 외재적 동기가 낮으면 내재적 동기와 창의성은 긍정적인 관계를 보이는 것으로 보고되었다.

본 연구에서의 창의성은 복잡하고 전문화된 기술을 필요로 하 는 질적인 성과뿐 아니라 일반적인 업무에서 창의적인 방식으로 문제를 해결하려는 노력도 포함하므로 승진과 급여 등과 같은 외 적 보상에 의해 동기부여 될수록 전반적으로 높은 창의성을 보일 것이라 예측하였다. 따라서 다음과 같은 가설을 설정하였다.

\section{<가설 2> 외재적 동기는 창의성에 긍정적인 영향을 미칠 것이다.}

\section{4. 조건적 보상의 조절효과}

조건적 보상(contingent reward)은 구성원이 특정한 성과를 달성하는 조건을 만족시켰을 때 제공되는 보상을 의미한다. 여 기서 보상은 외부로부터 주어지는 다양한 긍정적인 자극, 가령 승진, 성적, 포상, 칭찬, 인정 등을 망라하는 개념이다(Cerasoli et al., 2014). 보상은 두 가지 방식으로 구성원들의 행동에 영 향을 미친다. 첫째, 보상의 존재는 구성원들의 전반적인 동기 수준에 영향을 미치며 이는 구성원의 능력, 그리고 업무 및 조 직 설계 등과 함께 작용하여 성과 등과 같은 구성원의 행동을 
결정한다(Jadhav, Seetharaman, \& Rai, 2017). 둘째, 보상의 선별효과(sorting effect)는 서로 다른 유형의 보상이 서로 다른 유형의 사람들에게 영향을 미친다는 점을 강조하였다. 따라서 보상의 크기와 종류는 모두 중요하다 할 수 있다(Gerhart \& Fang, 2014).

조건적 보상은 크게 네 가지 유형으로 구분될 수 있다(Deci et al., 2001). 과업 비조건적 보상(task-noncontingent reward) 은 실험참가자에게 주는 보상과 같은 직무자체에 대한 몰입을 요구하지 않는 보상을 말한다. 완성 조건적 보상(completioncontingent reward)은 주어진 직무를 완성하였을 때 주는 보상, 참여 조건적 보상(engagement-contingent reward)은 직무에 참 여함으로써 주어지는 보상을 말한다. 마지막으로 성과 조건적 보상(performance-contingent reward)은 주어진 직무를 완벽한 수준 혹은 특정된 조건에 부합되게 수행하였을 때 주어지는 보상을 의미한다. Eisenberger and Shanock(2003)에 의하면 개인은 현재의 성과 중 어떠한 요소에 의해 보상을 받게 되는 지에 대해 학습하고 이를 새로운 활동에 적용하게 된다. 그러 므로 구성원이 창의성이 보상을 가져오는 성과 평가에 영향을 주는 요소 중의 하나라고 인식한다면 즉 보상이 창의적 업무 성과에 조건적으로 제공될 때 외적 보상과 창의성 간에 긍정 적인 상관관계가 존재할 수 있다고 하였다(Zhu et al., 2016). 특히 R\&D와 같이 창의성이 직무성과에 직접적인 영향을 주는 상황에서 조건적 보상은 외재적 동기를 높여 창의성을 제고하 는 역할을 할 수 있을 것이다(Montag, Maertz, \& Baer, 2012).

한편, 보상은 그 내용에 따라 무형의 보상(intangible reward) 과 유형의 보상(tangible rewards)으로 나눌 수 있다(Fahey, Vasconcelos, \& Ellis, 2007; Yoon, Sung, Choi, Lee, \& Kim, 2015)은 무형의 보상(intangible rewards)이란 상대적으로 관찰 되기 어렵고 측정이 어려운 보상으로, 가령 상사나 동료로부터 받는 칭찬이나 인정 등이 있다. 유형의 보상(tangible rewards) 이란 구체적이고 가시적이며 객관적으로 쉽게 측정할 수 있는 보상으로, 재정적인 보상과 승진 등이 이에 해당된다. 보상의 유 형이 내재적 동기에 미치는 영향에 관한 메타연구에서는 무형의 보상(예, 긍정적 피드백)은 내재적 동기에 긍정적인 영향을 미쳤 으며 유형의 보상은 내재적 동기에 부정적인 영향을 미쳤다. 더 불어 기대되지 않은 보상은 내재적 동기에 유의미한 영향을 미 치지 않았으나 기대된 보상은 내재적 동기에 부정적인 영향을 미치는 것으로 나타났다(Deci, Koestner, \& Ryan, 1999).

이는 인지평가이론(cognitive evaluation theory, CET: Deci \& Ryan, 1985)에 의해 설명될 수 있다. 인지평가이론은 내재적 동 기로 수행하는 과업에 보상을 제공하였을 경우 오히려 과업에 대한 동기가 저하되는 과잉정당화효과(overjustification effect)를 설명하는 이론이다 (Pretty \& Selligman, 1984). 일반적으로 보상 은 정보적(informational)인 기능과 통제적(controlling)인 기능이 있 는데, 이는 역량(competence)과 자기결정(self-determination)에 대한 심리적인 욕구 즉, 내재적 동기에 차별적인 영향을 주게 된다. 역량은 자신이 어떤 과업을 잘 수행할 수 있는 능력이 있 다고 지각하는 상태를 말하며, 자기결정이란 자신의 일에 대해 스스로가 결정하고 통제하고 있다는 인식이다. 보상의 정보적인 측면이 부각되면 개인의 역량에 대한 긍정적인 피드백을 전달하 여 내재적 동기를 높일 수 있으나, 통제적인 측면이 부각되면 인과소재(locus of causality)를 외부로 지각하게 되어 낮은 자기 결정성을 인식하게 되므로 내재적 동기가 감소될 수 있다(Deci et al., 2001). 일반적으로 승진, 금전 인센티브와 같은 유형의 보상은 통제적인 기능이 강한데 비해 칭찬, 인정 같은 무형의
보상은 정보적인 기능이 상대적으로 더 강조된다고 할 수 있다 (Deci \& Ryan, 2000).

우선, 직무 자체의 즐거움으로 인해 직무를 수행하는 구성원 이거나 외적인 보상을 얻기 위해 직무를 수행하는 구성원은 모 두 상사나 동료의 인정과 긍정적인 피드백 등 무형의 보상을 받 으면 자신의 역량에 대해 긍정적인 인식을 갖게 되어 보다 창의 적인 성과를 위해 더 많은 노력을 투입할 것으로 기대된다. 따 라서 무형의 조건적 보상이 동기가 창의성에 미치는 영향이 더 강하게 나타날 것으로 기대된다. 이에 근거하여 아래와 같은 가 설을 제기한다.

<가설 3> 무형의 보상은 내재적 동기와 창의성의 관계를 강화하는 방향으로 조절할 것이다. 즉 무형의 보 상이 커질수록, 내재적 동기와 창의성 간의 정 $(+)$ 의 관계가 강화될 것이다.

<가설 4> 무형의 보상은 외재적 동기와 창의성의 관계를 강화하는 방향으로 조절할 것이다. 즉 무형의 보 상이 커질수록, 외재적 동기와 창의성 간의 정 $(+)$ 의 관계가 강화될 것이다.

이에 반해 유형의 보상은 일반적으로 행동에 대한 유인책으 로 제공되어 통제적인 기능이 강조되는 경향이 있다(Latham \& Locke, 2007; Putwain \& Symes, 2011). 외적인 보상을 얻기 위해 업무를 수행했다고 지각하게 되므로 자기결정성이 저하 되고 이는 내재적 동기가 높은 구성원들에 부정적으로 작용할 것으로 보인다. 하지만 구성원들은 무조건적으로 보상을 통제 나 제약적인 요소로 생각하는 것은 아니다(Latham \& Locke, 2007). Vroom(1964)의 기대이론(expectancy theory)에 의하면 성과를 달성하면 인센티브와 같은 유형의 보상을 얻게 된다고 기대할 때 개인은 표적 행동을 수행하는 것을 수단으로 그 보 상을 얻으려 한다(Baer \& Frese, 2003; Jeffrey \& Adomza, 2010; Malik, Butt, \& Choi, 2015). 자기조절이론(self-regulatory theory) 역시 성과에 대한 인센티브가 주어지면 인센티브를 얻 기 위해 요구되는 성과를 달성하기 위하여 더 많은 노력을 기 울이게 된다고 주장한다(Carver, 2001; Eisenberger \& Aselage, 2009). 보상의 이러한 도구적인 기능은 업무 과정 또는 제품과 관련된 제안 및 아이디어가 필요한 조직에서 구성원의 창의성 을 자극할 수 있다(Lopez-Cabrales, Pérez-Luño, \& Cabrera, 2009). 특히, 급여, 승진 등 구체적인 보상으로부터 동기부여 가 되는 외재적 동기가 높은 구성원은 유형의 보상이 더 많이 주어질수록 창의적 업무수행을 위한 노력을 더 많이 기울일 것이다. 따라서 아래와 같은 가설을 제안한다.

<가설 5> 유형의 보상은 내재적 동기와 창의성의 관계를 약화하는 방향으로 조절할 것이다. 즉 유형의 보 상이 커질수록, 내재적 동기와 창의성 간의 정 $(+)$ 의 관계가 약화될 것이다.

<가설 6> 유형의 보상은 외재적 동기와 창의성의 관계를 강화하는 방향으로 조절할 것이다. 즉 유형의 보 상이 커질수록, 외재적 동기와 창의성 간의 정 $(+)$ 의 관계가 강화될 것이다.

이상 논의한 가설들을 종합하여 연구모형으로 나타내면 $<$ Figure $1>$ 과 같다. 


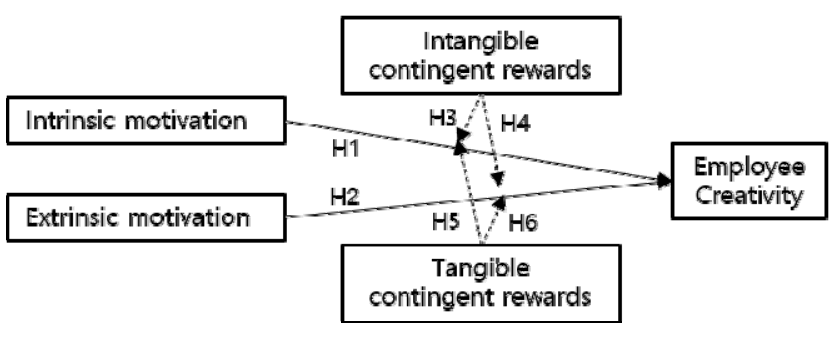

<Figure 1> Research Model

\section{3. 연구방법론}

\section{1. 자료수집 및 연구대상의 특성}

한국의 리서치회사에 등록되어 있는 다양한 산업군에 속한 기업체 종사자들을 대상으로 온라인 설문을 배포하여 자료를 수집하였다. 본 연구가 조직구성원의 창의성에 주 관심을 두고 있는 만큼 창의성과 관련 없는 직무나 직장에 종사하는 사람 들은 사전 질문을 통해 걸러내고 총 305 부의 설문지를 회수하 였으며, 추가로 불성실한 응답 27부를 제외하고 나머지 278부 를 통계분석에 사용하였다.

표본의 인구통계학적 특성은 여자는 107 명이고 남자는 171 명이며, 연령은 30 대가 128 명(46.04\%)로 가장 큰 비율을 차지 하고, 40 대가 82 명(29.50\%), 20대가 36 명(12.95\%), 50대 이상 이 32 명 $(11.51 \%)$ 로 가장 적게 나타났다. 직급은 사원/주임이 51 명 $(18.35 \%)$, 대리가 51명(18.35\%), 과장이 77 명 $(27.69 \%)$, 차장이 48명(17.26\%), 부장이 34명(12.23\%), 임원이 17명 $(6.11 \%)$ 으로 나타났다. 회사규모 정보에 따르면 소기업 근무자 가 69 명(24.82\%), 중소기업 근무자가 106 명(38.13\%)으로 가장 큰 비율을 차지하였고, 중견기업 근무자가 53명(19.06\%), 대기 업 근무자가 50 명(18.98\%)으로 나타났다.

<Table 1> Sample Characteristics

\begin{tabular}{|c|c|c|c|}
\hline & Category & Frequency & Percentage(\%) \\
\hline \multirow{4}{*}{ Gender } & Female & 107 & 38.50 \\
\hline \multirow{4}{*}{ Age } & Male & 171 & 61.51 \\
\cline { 2 - 4 } & $20-29$ & 36 & 12.95 \\
\cline { 2 - 4 } & $30-39$ & 128 & 46.04 \\
\cline { 2 - 4 } & $40-49$ & 82 & 29.50 \\
\hline \multirow{4}{*}{ Position } & 50 and above & 32 & 11.51 \\
\cline { 2 - 4 } & Staff & 51 & 18.35 \\
\cline { 2 - 4 } & Deputy section chief & 51 & 18.35 \\
\cline { 2 - 4 } & Section chief/head & 77 & 27.69 \\
\cline { 2 - 4 } & Deputy Department head & 48 & 17.26 \\
\cline { 2 - 4 } & Department head & 34 & 12.23 \\
\cline { 2 - 4 } & Higher than department head & 17 & 6.11 \\
\hline \multirow{4}{*}{ Firm size } & Small & 69 & 24.82 \\
\cline { 2 - 4 } & Small-to-medium & 106 & 38.13 \\
\cline { 2 - 4 } & Medium-to-large & 53 & 19.06 \\
\cline { 2 - 4 } & Large & 50 & 18.98 \\
\hline
\end{tabular}

\section{2. 변수의 조작적 정의 및 측정}

인구통계학적 특성에 대한 문항을 제외한 모든 변수는 리커 트(Likert) 5점 척도(1 = 전혀 그렇지 않다, 2 = 그렇지 않다, $3=$ 보통이다, $4=$ 그렇다, $5=$ 매우 그렇다)를 사용하여 측정 하였다. 사용된 전체 설문 문항은 부록 1 에 제시하였다.

\subsection{1. 창의성}

창의성은 조직에 새롭고 유용한 아이디어나 기술, 서비스 및 절차를 제안하는 행동으로 정의된다. 측정문항은 Zhou and George(2001)의 문항을 기존 한국 연구자들이 번안한 문항을 사용하였다. "나는 목표 달성을 위해 새로운 방식을 제안한다.", "나는 새로운 기술, 프로세스(공정), 기법, 제품 아이디어 등을 탐색한다." 등 13문항에 대해 자기보고 하였다(Cronbach's $\alpha=$ 0.94).

\subsection{2. 내재적 동기}

내재적 동기는 일 자체가 흥미롭고, 매력적이며, 만족스럽기 때문에 그 일을 수행하려는 욕구로 정의된다. Zhu, Gardner, and Chen(2016)이 사용한 "내가 매일 일하러 가는 이유는 직 무 자체를 즐기기 때문이다." 등 4문항이 사용되었다 (Cronbach's $\alpha=0.88$ ).

\subsection{3. 외재적 동기}

외재적 동기는 급여, 승진, 보너스, 직업 안정성 등 업무 외적 요인 때문에 그 일을 수행하려는 욕구로 정의된다. Manolopoulos (2006)가 개발하고 Zhu, Gardner, and Chen(2016)이 사용한 "내가 매일 일하러 가는 원인은 급여 때문이다." 등 4문항으로 측정하였다(Cronbach's $\alpha=0.67)$.

\subsection{4. 무형의 보상}

무형의 보상은 창의적인 업무수행으로 상사나 동료로부터 받는 칭찬이나 인정 등으로 정의하였다. 측정문항은 Ryan and Deci (2000), Deci et al.(1999) 등이 개발한 문항에 의거하여 Yoon et al.(2015), Malik et al.(2015) 등이 사용한 "내가 혁신 적인 아이디어를 제공하면 나의 동료들은 나를 인정하고 격려 한다.” 등 3 문항을 역번역 과정을 거쳐 한국어로 번역 후 사용 하였다(Cronbach's $\alpha=0.86$ ).

\subsection{5. 유형의 보상}

유형의 보상은 창의적인 업무수행을 조건으로 받는 인센티 브, 보너스, 수입 등으로 정의하였다. 측정문항은 마찬가지로 Yoon et al.(2015), Malik et al.(2015) 등이 사용한 "내가 직장 에서 창의적으로 수행한다면 추가적인 재정적 인센티브를 받 는다." 등 4문항을 역번역 과정을 거쳐 한국어로 번역 후 사용 하였다(Cronbach's $\alpha=0.79$ ).

\subsection{6. 인구통계학적 변수}

인구통계학적 변수의 경우, 동기나 창의성과 유의미한 관계 가 있을 것으로 예상되는 성별, 연령, 직급, 회사규모에 대해 설문문항을 통해 수집하였다. 


\section{4. 연구 결과}

\section{1. 타당도 분석}

본 연구에서 사용된 측정도구의 타당도를 확인하기 위해 SPSS AMOS 20을 사용하여 확인적 요인분석을 실시하였다. 먼저, 본 연구모형에 포함된 5 개 변수들을 각각의 잠재변수로 설정한 5 요인 모형과 내재적 동기와 외재적 동기를 하나의 요 인으로 묶고, 무형의 보상과 유형의 보상을 하나의 요인으로 묶은 3요인 모형, 모든 문항을 하나의 요인으로 묶은 1요인 모형의 적합도 지수를 살펴보았다. 5 요인 모형의 적합도 지수 를 살펴보면, $\chi^{2}=620.96, \quad \mathrm{df}=332, \mathrm{NFI}=.873, \mathrm{GFI}=.864$, $\mathrm{CFI}=.936, \mathrm{RMSEA}=.056$ 으로 다른 모형들에 비해 수용 가능한 적합도 수준을 보이고 있다. 또한, 5요인 모형과 단일 요인 모 형의 $\chi^{2}$ 값의 차이가 $371.993(\triangle \mathrm{df}=15)$ 로 $99.9 \%$ 신뢰수준에서 통계적으로 유의한 차이를 보여주었다.

모든 변수에 대한 측정데이터를 단일한 원천(single source) 에서 얻었기 때문에 발생할 수 있는 동일방법편의(common method bias) 문제를 확인하기 위해 Harman's single-factor test를 실시하였다(Podsakoff, MacKenzie, Lee, \& Podsakoff, 2003). 요인분석 결과 단일 요인이 추출되거나 단일 요인이 전체 분산의 $50 \%$ 이상을 설명하게 되면 동일방법을 사용한 것이 결과의 타당도를 위협한다고 볼 수 있다. 본 연구의 데이 터로 탐색적 요인 분석을 실시한 결과, 고유값이 1 이상인 5 개의 요인이 추출되었으며 요인의 개수를 1 개로 한정한 경우 에도 단일 요인이 설명하는 변량은 $38.71 \%$ 로 나타나 동일방 법 편의 문제는 우려할 수준이 아니라고 판단된다.

<Table 2> Confirmatory Factor Analysis

\begin{tabular}{|c|c|c|c|c|c|c|}
\hline Model & $\mathbf{X}$ & df & NFI & GFI & CFI & RMSEA \\
\hline $\begin{array}{c}\text { Research model } \\
\text { (5 factors) }\end{array}$ & $620.959^{\star \star *}$ & 332 & .873 & .864 & .936 & .056 \\
\hline $\begin{array}{c}\text { Alternative model1 } \\
\text { (3 factors) }\end{array}$ & $992.952^{\star \star *}$ & 347 & .797 & .774 & .857 & .082 \\
\hline $\begin{array}{c}\text { Alternative model2 } \\
\text { ( } 1 \text { factor) }\end{array}$ & $1952.563^{\star * \star}$ & 350 & .602 & .560 & .646 & .129 \\
\hline
\end{tabular}

\section{2. 기술통계 및 상관관계분석}

본 연구에서 사용된 변수들의 기술통계와 상관관계 분석 결 과는 <Table 1>에 제시되어 있다. 먼저 내재적 동기는 성별 $(r=.12)$, 연령과 $(r=.22)$ 의 정적 상관을 보였다. 직급의 경우, 부 장은 $(r=.12)$, 임원은 $(r=.14)$ 로 사원에 비해 내재적 동기가 높 은 것으로 나타났다. 반면에 외재적 동기는 성별과 $(r=.15)$ 의 정적 상관을 보였고 이는 남성이 여성에 비해 외재적 동기가 높음을 보여준다. 또 회사규모에 따라서 보면 대기업은 $(r=.20)$ 로 소기업에 비해 외재적 동기가 높게 나타나는 것을 알 수 있다. 관심 결과변수인 창의성은 성별과 $(r=.24)$, 연령과 $(\mathrm{r}=.15)$ 의 정적 상관을 보였다. 이는 남성이 여성에 비해 창의 성이 높게 나타나고 연령이 높을수록 창의적 업무수행을 높게 보고한다는 것을 알 수 있다. 또한 창의성 역시 직급에 따라 다르게 나타났으며 차장은 $(r=.16)$, 임원은 $(r=.17)$ 로 사원에 비 해 창의성이 높다는 것을 알 수 있다.

다음으로 가설 관련 변수들을 살펴보면, 내재적 동기는 창 의성과 $(r=.46))$, 외재적 동기와 창의성은 $(r=.31)$ 의 상관이 나 타났다. 또한 무형의 보상과 창의성은 $(r=.53)$, 유형의 보상과 창의성은 $(r=.46)$ 으로 나타났다. 이는 내재적 동기와 외재적 동 기가 높을수록 창의성이 높아지며, 무형과 유형의 조건적 보상 역시 창의성과 정적인 상관을 보임을 알 수 있다.

\section{3. 가설 검증 결과}

연구가설에서 살펴보고자 하는 변수들 간의 관계를 명확하 게 살펴보기 위하여 인구통계학적 변수인 성별, 나이, 직급, 회사규모를 통제변수로 사용하여 위계적회귀분석(hierarchical linear regression)을 실시하였다. 분석과정에서 독립변수들 간 의 다중공선성의 존재 여부를 판단하기 위하여 모든 변수들의 공차한계(tolerance)와 분산팽창지수(VIF)를 확인한 결과, 모든 변수가 공차한계 .30 이상, VIF 3.0 이하의 값을 보여 변수들 간의 다중공선성 문제는 없는 것으로 판단된다.

<Table 3> Descriptive Statistics and Correlation Analysis

\begin{tabular}{|c|c|c|c|c|c|c|c|c|c|c|c|c|c|c|c|c|}
\hline Variables & $\mathbf{M}$ & SD & 1 & 2 & 3 & 4 & 5 & 6 & 7 & 8 & 9 & 10 & 11 & 12 & 13 & 14 \\
\hline 1. Gender & 0.62 & 0.49 & 1 & & & & & & & & & & & & & \\
\hline 2. Age & 38.97 & 8.51 & $.35^{\star *}$ & 1 & & & & & & & & & & & & \\
\hline 3. Position1 & 0.18 & 0.39 & $-.20^{\star \star}$ & $-.29^{\star \star}$ & 1 & & & & & & & & & & & \\
\hline 4. Position2 & 0.28 & 0.45 & .06 & .03 & $-.29^{\star \star}$ & 1 & & & & & & & & & & \\
\hline 5. Position3 & 0.17 & 0.38 & $.17^{\star *}$ & $.20^{* *}$ & $-.22^{\star \star}$ & $-.28^{\star *}$ & 1 & & & & & & & & & \\
\hline 6. Position4 & 0.12 & 0.33 & $.23^{\star *}$ & $.33^{\star \star}$ & $-.18^{\star \star}$ & $-.23^{\star \star}$ & $-.17^{\star \star}$ & 1 & & & & & & & & \\
\hline 7. Position5 & 0.06 & 0.24 & $.14^{*}$ & $.36^{\star *}$ & $-.12^{*}$ & $-.16^{\star *}$ & -.12 & -.10 & 1 & & & & & & & \\
\hline 8. Firm Size1 & 0.38 & 0.49 & -.05 & .10 & .01 & $-.12^{\star}$ & -.03 & .00 & $.26^{\star \star}$ & 1 & & & & & & \\
\hline 9. Firm Size2 & 0.19 & 0.39 & .06 & -.06 & -.02 & .11 & -.00 & .01 & $-.12^{*}$ & $-.38^{* *}$ & 1 & & & & & \\
\hline 10. Firm Size3 & 0.18 & 0.39 & $.14^{*}$ & -.09 & .12 & .09 & -.02 & -.06 & $-.12^{*}$ & $-.37^{\star \star}$ & $-.23^{\star *}$ & 1 & & & & \\
\hline 11. Intrinsic Motivation & 2.94 & 0.81 & $.12^{*}$ & $.22^{\star \star}$ & $-.19^{\star \star}$ & .11 & .05 & $.12^{*}$ & $.14^{*}$ & -.06 & .09 & .06 & 1 & & & \\
\hline 12. Extrinsic Motivation & 2.75 & 0.86 & $.15^{*}$ & .03 & .01 & .03 & .03 & .00 & .04 & -.09 & .09 & $.20^{* *}$ & $.28^{* \star}$ & 1 & & \\
\hline 13. Intangible rewards & 3.16 & 0.78 & $.19^{\star \star}$ & $.13^{*}$ & -.08 & -.06 & .11 & .07 & $.18^{* *}$ & -.04 & .04 & .11 & $.47^{\star \star}$ & $.35^{\star \star}$ & 1 & \\
\hline 14. Tangible rewards & 2.63 & 0.87 & $.27^{* *}$ & $.14^{*}$ & $-.12^{*}$ & -.07 & .12 & .12 & $.16^{* *}$ & -.07 & $.14^{*}$ & .11 & $.52^{\star \star}$ & $.50^{\star *}$ & $.71^{\star *}$ & 1 \\
\hline 15. Creativity & 3.26 & 0.66 & $.24^{\star *}$ & $.15^{*}$ & -.10 & -.01 & $.16^{\star \star}$ & .10 & $.17^{* *}$ & -.09 & $.17^{* *}$ & .10 & $.46^{\star *}$ & $.31^{* *}$ & $.53^{\star *}$ & $.46^{* *}$ \\
\hline
\end{tabular}

${ }^{*} \mathrm{~N}=278 .{ }^{*} \mathrm{p}<.05,{ }^{* *} \mathrm{p}<.01$, two-sided

** Gender(0=female; 1=male), Position(reference: staff, 1: deputy section chief, 2: section chief, 3: deputy department chief, 4: department head, 5: higher than department head), Firm size(reference: small, 1: small-to-medium, 2: medium-to-large, 3: large) 


\subsection{1. 외재적, 내재적 동기와 창의성}

먼저 <가설 1>과 <가설 2>을 검증하기 위해 두 가지 동기 유형과 창의성의 관계를 분석하였다. 아래의 <Table 2>를 보 면 통제변수인 직급 중 과장 $(\beta=0.27, p<0.05), \quad$ 차장 $(\beta=0.57$, $p<0.001)$, 부장 $(\beta=0.55, p<0.01), \quad$ 임원 $(\beta=0.94, p<0.001)$ 은 사 원/주임에 비해 창의성이 높다는 것을 알 수 있다. 회사규모를 보면, 중견기업 $(\beta=0.39, p<0.01)$ 과 대기업 $(\beta=0.31, p<0.31)$ 은 소기업에 비해 창의성이 높게 나타나는 것을 알 수 있다. 이는 직급이 높고 회사규모가 클수록 개인의 창의성이 높게 나타남 을 보여준다.

<Table 2>에서 보듯이, 모형 2와 모형 3 의 $\mathrm{R}^{2}$ 는 각각 0.32 , 0.24 로 나타났으며 $\mathrm{F}$ 값은 각각 $11.27,7.61$ 로 유의미한 설명력 을 보였다. 구체적으로 내재적 동기 $(\beta=0.31, p<0.001)$ 와 외재 적 동기 $(\beta=0.18, p<0.001)$ 는 모두 창의성에 유의미한 정 $(+)$ 의 영향을 미치는 것으로 나타났다. 또한 내재적 동기와 외재적 동기를 동시에 투입한 모형 4에서도 이러한 효과는 지속되었 으며 창의성에 대한 영향이 외재적 동기 $(\beta=0.12, p<0.01)$ 에 비 해 내재적 동기 $(\beta=0.28, p<0.001)$ 가 더 높음을 알 수 있다. 따 라서 <가설 1>과 <가설 2>는 지지되었다.

\subsection{2. 조건적 보상, 유형의 보상과 무형의 보상의 조절효과}

본 연구에서는 조절효과를 검증하기 위하여 위계적 회귀분 석(hierarchial regression analysis) 방법을 활용하였다. 이는 회귀식에 변수들을 단계적으로 투입하는 과정에서 조절변수와 독립변수 간의 상호작용항을 추가했을 때 설명력 $\left(R^{2}\right)$ 이 통계적 으로 유의하게 증가하는지를 확인하는 기법이다. 조절효과를 검증함에 있어서 다중공선성이 존재할 것을 고려하여 변수를 평균중심화(mean centering)하여 상호작용항을 만들었다.

<Table 2>의 모형 4를 보면 내재적 동기와 외재적 동기를 투입하였을 때 $R^{2}$ 는 0.34 로 증가하였다. 모형 5 에서 무형의 보상과 유형의 보상이 추가 투입되었을 때 $R^{2}$ 는 0.41 로 증가 하였고, 상호작용항을 투입한 모형 6 의 $R^{2}$ 는 0.44 로 증가하였
고 $\mathrm{F}$ 변화량의 유의확률이 0.01 의 유의수준을 충족하였다. 독 립변수인 외재적, 내재적 동기와 조절변수인 유형, 무형의 보 상이 모두 투입된 모형 5 에서는 내재적 동기 $(\beta=0.19, p<0.001)$ 와 무형의 보상 $(\beta=0.30, p<0.001)$ 만이 유의미한 영향을 미쳤 다. 모형 6 에서 동기유형과 보상유형의 4 가지 상호작용항을 만들어 투입한 결과, 내재적 동기와 무형의 보상의 상호작용항 $(\beta=-0.05, p>0.05)$ 과 내재적 동기와 유형의 보상의 상호작용항 $(\beta=0.11, p>0.05)$ 은 유의미하지 않은 것으로 나타나 <가설 $3>$ 과 <가설 5>는 기각되었다. 외재적 동기와 무형의 보상의 상 호작용항 $(\beta=-0.19, p<0.05)$, 외재적 동기와 유형의 보상의 상호 작용항 $(\beta=0.17, p<0.01)$ 은 유의미한 것으로 나타났다.

조절효과를 보다 명확하게 알아보기 위하여 Aiken and West(1991)가 제안한 방식으로 상호작용 그래프를 그려보았 다. <Figure 2>에서 보면 무형의 보상이 높은 경우에 외재적 동기와 창의성은 부(-)적인 관계를 보이고 낮은 경우에 정(+)적 인 관계를 보인다. 따라서 무형의 보상이 커질수록, 외재적 동 기와 창의성 간의 정(+)의 관계는 더 강하게 나타날 것이라는 <가설 4>는 기각되었다.

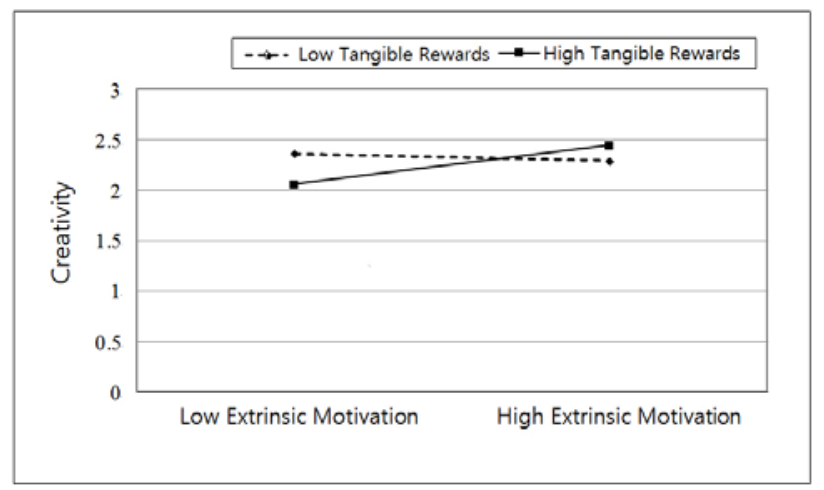

<Figure 2> Effect of extrinsic motivation and intangible rewards on creativity

<Table 4> Hierarchical Regression Analysis for Hypotheses Testing

\begin{tabular}{|c|c|c|c|c|c|c|}
\hline \multirow{2}{*}{ Variable } & \multicolumn{6}{|c|}{ DV: Creativity } \\
\hline & Model 1 & Model 2 & Model 3 & Model 4 & Model 5 & Model 6 \\
\hline (Constant) & $3.06^{* \star *}$ & $2.31^{* \star \star}$ & $2.63^{* \star *}$ & $2.11^{\star \star *}$ & $1.63^{* \star *}$ & $1.66^{* * *}$ \\
\hline Gender & 0.11 & 0.14 & 0.08 & 0.12 & 0.09 & 0.09 \\
\hline Age & -0.01 & -0.01 & -0.01 & -0.01 & -0.01 & -0.08 \\
\hline Position1 & 0.14 & 0.17 & 0.12 & 0.16 & 0.14 & 0.14 \\
\hline Position2 & $0.27^{*}$ & 0.16 & $0.25^{*}$ & 0.16 & 0.17 & 0.17 \\
\hline Position3 & $0.57^{* \star *}$ & $0.47^{\star \star \star}$ & $0.55^{\star \star \star}$ & $0.47^{* \star}$ & $0.40^{\star *}$ & $0.41^{\star \star}$ \\
\hline Position4 & $0.55^{\star \star}$ & $0.39^{*}$ & $0.54^{\star *}$ & $0.40^{*}$ & $0.36^{*}$ & $0.38^{\star *}$ \\
\hline Position5 & $0.94^{* * *}$ & $0.71^{* * *}$ & $0.88^{\star \star \star}$ & $0.70^{* \star *}$ & $0.56^{* *}$ & $0.62^{* *}$ \\
\hline Firm Size1 & 0.03 & 0.03 & 0.01 & 0.02 & 0.03 & 0.04 \\
\hline Firm Size2 & $0.39^{* *}$ & $0.31^{* *}$ & $0.32^{* *}$ & $0.27^{\star *}$ & $0.28^{\star *}$ & $0.28^{\star \star}$ \\
\hline Firm Size3 & $0.31^{* \star *}$ & $0.22^{*}$ & 0.21 & 0.17 & 0.15 & 0.14 \\
\hline Intrinsic Motivation (IM) & & $0.31^{* \star \star}$ & & $0.28^{\star * \star}$ & $0.19^{* \star \star}$ & $0.19^{\star \star \star}$ \\
\hline Extrinsic Motivation (EM) & & & $0.18^{\star \star \star}$ & $0.12^{* \star}$ & 0.07 & 0.08 \\
\hline Intangible Rewards (IR) & & & & & $0.30^{\star * *}$ & $0.27^{\star \star *}$ \\
\hline Tangible Rewards (TR) & & & & & -0.05 & -0.04 \\
\hline IM"IR & & & & & & -0.05 \\
\hline$E M^{*} I R$ & & & & & & $-0.19^{*}$ \\
\hline $\mathrm{IM}^{*} \mathrm{TR}$ & & & & & & 0.11 \\
\hline$E M^{*} T R$ & & & & & & $0.17^{\star \star}$ \\
\hline R2 & 0.19 & 0.32 & 0.24 & 0.34 & 0.41 & 0.44 \\
\hline$\triangle \mathrm{R} 2$ & & 0.13 & 0.05 & 0.15 & 0.08 & 0.03 \\
\hline$F$ for $\triangle R 2$ & & $50.72^{\star \star \star}$ & $18.05^{\star \star \star}$ & $29.90^{* \star \star}$ & $16.61^{* \star \star}$ & $3.62^{* *}$ \\
\hline overall $\mathrm{F}$ & $6.17^{\star \star \star}$ & $11.27^{\star \star \star}$ & $7.61^{\star \star \star}$ & $11.24^{\star \star *}$ & $13.14^{\star \star *}$ & $11.43^{\star \star *}$ \\
\hline
\end{tabular}

${ }^{*} \mathrm{~N}=278 .{ }^{*} \mathrm{p}<.05,{ }^{* *} \mathrm{p}<.0001$. 
<Figure 3>을 보면 유형의 보상이 높은 경우에 외재적 동기 와 창의성은 정(+)적인 관계를 보이고 낮은 경우에 부(-)적인 관계를 보인다. 따라서 유형의 보상이 커질수록, 외재적 동기 와 창의성 간의 정(+)의 관계는 더 강하게 나타날 것이라는 가 설 6은 지지되었다. 즉, 유형의 보상이 제공될 때 외재적 동기 가 높을수록 창의성이 더 높아짐을 알 수 있다.

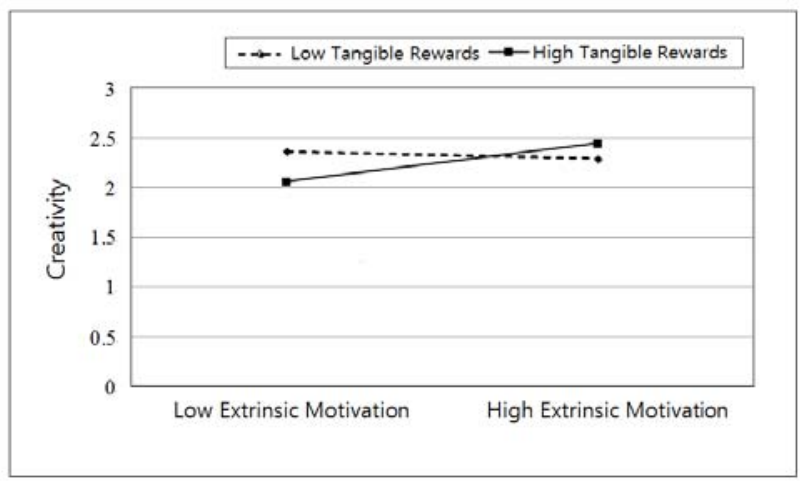

<Figure 3> Effect of extrinsic motivation and tangible rewards on creativity

\section{5. 결론 및 시사점}

\section{1. 연구결과 및 시사점}

본 연구는 내재적 동기와 외재적 동기가 창의성에 미치는 영향과 무형과 유형의 보상의 조절효과를 검증하였다. 실증분 석을 통해 도출된 결과를 근거로 하여 연구의 결론을 정리하 면 다음과 같다.

첫째, 내재적 동기와 외재적 동기는 창의성에 긍정적인 영 향을 미칠 것이라는 <가설 1>과 <가설 2>는 모두 지지되었다. 내재적 동기가 창의성에 미치는 긍정적인 영향은 기존 연구 (Bodla \& Naeem, 2014; Dewett, 2007; Grant \& Berry, 2011) 에서 반복적으로 검증되어 온 결과이다. 실제로 본 연구에서 내재적 동기와 외재적 동기가 창의성에 미치는 영향을 동시에 살펴보았을 때 내재적 동기의 효과가 더 크게 나타났다. 이는 조직구성원의 창의성을 높이는데 내재적 동기가 매우 일관되 고 강력한 효과를 지님을 다시 한 번 확인해주는 결과이다. 한 편, 본 연구의 더 큰 의의는 외재적 동기가 창의성에 미치는 긍정적인 영향을 확인하였다는 데 있다. 과거 창의성과 관련하 여 외재적 동기의 역할에 대해서는 다소 상반된 연구결과들이 도출되어 왔는데(Baer, Oldham \& Cummings, 2003; Deci \& Ryan, 1985; Eisenberger, Haskins \& Gambleton, 1999), 본 연구에서는 외재적 동기가 높은 직장인들이 창의성도 높은 경 향이 있음을 보여주어 비록 내재적 동기에 비해 상대적으로 낮은 영향력을 가지지만 외재적 동기 또한 창의성을 높이는 데 있어서 유의미한 역할을 할 수 있음을 보여준다.

둘째, 조건적 보상이 동기와 창의성의 관계를 조절할 것이 라는 가설은 일부 지지되었다. 구체적으로 무형과 유형의 보상 모두 내재적 동기와 창의성의 관계를 유의미하게 조절하지 않 았다. 이는 내재적 동기가 창의성을 예측하는 중요한 변수이지
만, 외적인 보상이 주어지면 내재적 동기의 효과가 감소한다는 주장(Cerasoli et al., 2014; Hendijani et al., 2016; Zhu et al., 2016)과는 다른 결과이다. 이는 내재적으로 동기부여가 된 구 성원은 직무자체에서 오는 만족, 재미 혹은 도전에 의해 직무 를 수행하기 때문에(Aletraris, 2010; Ryan \& Deci, 2000) 성과 에 대한 조건적 보상 등 상황변수의 영향을 상대적으로 적게 받기 때문이라고 추론할 수 있다.

셋째, 유형, 무형의 조건적 보상은 외재적 동기와 창의성의 관계에 유의미한 조절효과를 보여주었다. 유형의 보상은 가설 에서 제기한 바와 같이 외재적 동기와 창의성의 관계를 강화 하는 것으로 나타나 <가설 $6>$ 은 지지되었다. 이는 예측한 바 와 같이 승진, 급여 등 유형의 보상을 위해 직무를 수행하는 구성원에게 그 기대에 상응하는 유형의 보상을 제공하면 더 높은 창의성을 보인다는 것을 확인할 수 있다. 한편, 무형의 보상은 외재적 동기의 효과를 약화시키는 것으로 나타나 <가 설 $4>$ 에서 기대한 방향과는 반대의 결과가 도출되었다. 이는 외재적 동기가 높은 구성원은 대개 보너스, 승진과 같이 명확 한 유형의 보상을 선호한다는 점을 고려할 때 무형의 보상이 실질적으로 창의적인 업무수행을 위한 노력을 증대 시키는 효 과는 미미할 수 있음을, 무형의 보상은 오히려 외재적 동기가 낮은 구성원에게 효과적인 도구일 수 있음을 시사한다.

이러한 연구결과는 다음과 같은 이론적, 실무적 시사점을 제공한다.

첫째, 기존 동기와 창의성 연구들은 내재적 동기의 중요성 을 지나치게 강조하고 외재적 동기의 영향을 상대적으로 간과 하는 경향이 있었다. 본 연구결과는 학교나 취미활동과 달리 외적 보상의 중요성을 무시할 수 없는 기업조직 안에서는 내 재적 동기 뿐 아니라 외재적 동기도 창의성에 중요한 영향을 미친다는 것을 확인해주었다(Yang, Cho, \& Lee, 2015). 따라 서 Deci and Ryan(1985)이 "인간행동의 많은 부분은 내재적인 동기와 무관하게 발생한다.”고 강조했듯이, 외재적 동기를 효 과적으로 고취시키는 방안에 대해서도 보다 많은 관심을 기울 일 필요가 있다.

둘째, 실무적으로 조직관리자와 인사실무자는 구성원의 동 기 유형에 따라 동기부여에 효과적인 보상의 종류가 무엇인지 고민하고 이에 따라 보상을 제공하는 시스템을 구축할 필요가 있다고 본다. 특히, 내재적 동기가 높은 구성원에 비해 외재적 동기가 높은 구성원의 경우, 제공되는 보상의 유형에 따라 성 과의 수준이 다르게 나타나므로 조직은 보상을 제공함에 있어 서 내재적 동기가 높은 구성원 보다 외재적 동기가 높은 구성 원에게 더욱 관심을 갖고 적합한 유형의 보상을 제공할 수 있 도록 보상체계를 마련해야 할 것이다. 보다 많은 자원이 필요 하고 제공이 상대적으로 어려운 유형의 보상(가령, 성과급이나 승진)을 상대적으로 값싸고 용이한 무형의 보상(가령, 칭찬이나 인정)으로 대체하는 시도는 외재적 동기가 높은 구성원의 창의 성을 높이지 못할 수 있음을 유념하여야 한다. 더 나아가서 회 사가 제공하는 보상이 구성원의 행동을 통제하는 수단으로 받 아들여져 개인의 역량과 자기결정성에 대한 인식을 손상시키지 않도록 긍정적인 피드백으로서 기능하는 보상의 정보적 가치를 전달하기 위해 세심한 노력을 기울일 필요가 있겠다.

\section{2. 연구의 한계와 제언}

본 연구의 한계점과 향후 연구방향은 다음과 같다.

첫째, 모든 변수를 자기보고 설문을 사용하여 측정하였기 
때문에 동일방법편의(common method bias)가 존재할 가능성 이 있다. 본 연구에서는 구성원이 스스로 평가하는 본인의 창 의적인 업무수행 정도를 창의성 지표로 활용하였으나 구성원 이 업무에서 보이는 창의성에 대한 보다 객관적인 측정을 위 해서는 상사나 동료 등의 타인평가(e.g., George \& Zhou, 2002; Tierney \& Farmer, 2004; Zhu et al., 2016)나 특허 개 수나 제안한 아이디어 개수(e.g., Oldham \& Cummings, 1996; Frese, Teng, \& Wijnen, 1999; Tierney et al., 1999)와 같은 객관적인 지표를 사용하여 검증할 필요가 있겠다.

둘째, 본 연구에서는 조건적 보상을 유형의 보상과 무형의 보상으로 크게 나누어 살펴보았는데 사실 보다 세분화된 분류 가 가능하다. 가령, 유형의 보상이라도 인센티브와 같은 금전 적 보상과 승진과 같은 비금전적 보상의 효과가 다를 수 있다. 물론 승진하게 되면 자연히 급여가 인상되지만 직접적으로 돈 을 보상으로 받는다고 인식하지는 않을 것이다. 이러한 보상의 보다 구체적인 특성들이 구성원의 창의성에 미치는 세분화된 영향을 연구할 필요가 있겠다.

마지막으로, 개인특성과 환경특성의 상호작용이 창의성에 미치는 영향에 대한 연구(e.g., Baer et al., 2003; Van Dyne, Jehn, \& Cummings, 2002)는 많이 이루어져왔으나, 서로 다른 환경특성 간의 상호작용이 창의성에 미치는 영향에 대한 연구 가 상대적으로 부족하다(Shalley \& Gilson, 2004). 예를 들면, Zhou(2003)는 비통제적이고 지지적인 상사가 구성원의 창의성 에 미치는 영향은 높은 창의성을 발휘하는 동료가 존재할 때 강화된다고 하였다. 이렇듯 개인을 둘러싼 하나 이상의 상황적 변수 간의 상호작용이 창의성에 미치는 영향에 대한 연구가 요구된다.

\section{References}

Aletraris, L. (2010). How satisfied are they and why? A study of job satisfaction, job rewards, gender and temporary agency workers in Australia. Human Relations, 63(8), 1129-1155.

Amabile, T. M. (1988). A model of creativity and innovation in organizations. Research in Organizational Behavior, 10(1), 123-167.

Amabile, T. M. (1997). Motivating creativity in organizations: On doing what you love and loving what you do. California Management Review, $40(1), 39-58$.

Amabile, T. M., Conti, R., Coon, H., Lazenby, J., \& Herron, M. (1996). Assessing the work environment for creativity. Academy of Management Journal, 39(5), 1154-1184.

Amabile, T. M., Hill, K. G., Hennessey, B. A., \& Tighe, E. M. (1994). The Work Preference Inventory: assessing intrinsic and extrinsic motivational orientations. Journal of Personality and Social Psychology, 66(5), 950.

Baer, M., \& Frese, M. (2003). Innovation is not enough: Climates for initiative and psychological safety, process innovations, and firm performance. Journal of Organizational Behavior, 24(1), 45-68.

Baer, M., Oldham, G. R., \& Cummings, A. (2003). Rewarding creativity: when does it really matter? The Leadership Quarterly, 14(4), 569-586.

Bodla, M. A., \& Naeem, B. (2014). Creativity as mediator for intrinsic motivation and sales performance. Creativity Research Journal, 26(4), 468-473.

Byron, K., \& Khazanchi, S. (2012). Rewards and creative performance: a meta-analytic test of theoretically derived hypotheses. Psychological Bulletin, 138(4), 809.

Cameron, J., Banko, K. M., \& Pierce, W. D. (2001). Pervasive negative effects of rewards on intrinsic motivation: The myth continues. The Behavior Analyst, 24(1), 1-44.

Carver, C. S. (2001). Affect and the functional bases of behavior: On the dimensional structure of affective experience. Personality and Social Psychology Review, 5(4), 345-356.

Cerasoli, C. P., Nicklin, J. M., \& Ford, M. T. (2014). Intrinsic motivation and extrinsic incentives jointly predict performance: A 40-year meta-analysis. Psychological Bulletin, 140(4), 980.

Cooper, R. B., \& Jayatilaka, B. (2006). Group creativity: The effects of extrinsic, intrinsic, and obligation motivations. Creativity Research Journal, 18(2), 153-172.

Deci, E. L., \& Ryan, R. M. (1985). The general causality orientations scale: Self-determination in personality. Journal of Research in Personality, 19(2),109-134.

Deci, E. L., \& Ryan, R. M. (2000). The "what" and "why" of goal pursuits: Human needs and the self-determination of behavior. Psychological Inquiry, 11(4), 227-268.

Deci, E. L., Koestner, R., \& Ryan, R. M. (1999). A meta-analytic review of experiments examining the effects of extrinsic rewards on intrinsic motivation. Psychological Bulletin, 125(6), 627.

Deci, E. L., Koestner, R., \& Ryan, R. M. (2001). Extrinsic rewards and intrinsic motivation in education: Reconsidered once again. Review of Educational Research, 71(1), 1-27.

Dewett, T. (2007). Linking intrinsic motivation, risk taking, and employee creativity in an R\&D environment. R\&D Management, 37(3), 197-208.

Eisenberger, R., \& Aselage, J. (2009). Incremental effects of reward on experienced performance pressure: Positive outcomes for intrinsic interest and creativity. Journal of Organizational Behavior, 30(1), 95-117.

Eisenberg, J., \& Thompson, W. F. (2011). The effects of competition on improvisers' motivation, stress, and 
creative performance. Creativity Research Journal, 23(2), 129-136.

Eisenberger, R., \& Shanock, L. (2003). Rewards, intrinsic motivation, and creativity: A case study of conceptual and methodological isolation. Creativity Research Journal, 15(2-3), 121-130.

Eisenberger, R., Haskins, F., \& Gambleton, P. (1999). Promised reward and creativity: Effects of prior experience. Journal of Experimental Social Psychology, 35(3), 308-325.

Fahey, R., Vasconcelos, A. C., \& Ellis, D. (2007). The impact of rewards within communities of practice: a study of the SAP online global community. Knowledge Management Research \& Practice, 5(3), 186-198.

Frese, M., Teng, E., \& Wijnen, C. J. (1999). Helping to improve suggestion systems: Predictors of making suggestions in companies. Journal of Organizational Behavior, 1139-1155.

Gagné, M., \& Deci, E. L. (2005). Self-determination theory and work motivation. Journal of Organizational Behavior, 26(4), 331-362.

George, J. M., \& Zhou, J. (2002). Understanding when bad moods foster creativity and good ones don't: The role of context and clarity of feelings. Journal of Applied Psychology, 87, 687-697.

Gerhart, B., \& Fang, M. (2014). Pay for (individual) performance: Issues, claims, evidence and the role of sorting effects. Human Resource Management Review, 24(1), 41-52.

Gong, Y., Cheung, S. Y., Wang, M., \& Huang, J. C. (2012). Unfolding the proactive process for creativity: Integration of the employee proactivity, information exchange, and psychological safety perspectives. Journal of Management, 38(5), 1611-1633.

Grant, A. M., \& Berry, J. W. (2011). The necessity of others is the mother of invention: Intrinsic and prosocial motivations, perspective taking, and creativity. Academy of Management Journal, 54(1), 73-96.

Guay, F., Vallerand, R. J., \& Blanchard, C. (2000). On the assessment of situational intrinsic and extrinsic motivation: The Situational Motivation Scale (SIMS). Motivation and Emotion, 24(3), 175-213.

Hendijani, R., Bischak, D. P., Arvai, J., \& Dugar, S. (2016). Intrinsic motivation, external reward, and their effect on overall motivation and performance. Human Performance, 29(4), 251-274.

Jadhav, V., Seetharaman, A., \& Rai, S. (2017). Employee expectation to demonstrate innovative work behaviour in Asia. The Journal of Asian Finance, Economics and Business, 4(1), 67-78.
Janssen, O., \& Van Yperen, N. W. (2004). Employees' goal orientations, the quality of leader-member exchange, and the outcomes of job performance and job satisfaction. Academy of management journal, 47(3), 368-384.

Jeffrey, S. A., \& Adomdza, G. K. (2010). Incentive salience and improved performance. Human Performance, 24(1), 47-59.

Kasof, J., Chen, C., Himsel, A., \& Greenberger, E. (2007). Values and creativity. Creativity Research Journal, 19(2-3), 105-122.

Koestner, R., Losier, G. F., Vallerand, R. J., \& Carducci, D. (1996). Identified and introjected forms of political internalization: Extending self-determination theory. Journal of Personality and Social Psychology, 70(5), 1025.

Latham, G. P., \& Locke, E. A. (2007). New developments in and directions for goal-setting research. European Psychologist, 12(4), 290-300.

Lopez-Cabrales, A., Pérez-Luño, A., \& Cabrera, R. V. (2009). Knowledge as a mediator between HRM practices and innovative activity. Human Resource Management, 48(4), 485-503.

Malik, M. A. R., Butt, A. N., \& Choi, J. N. (2015). Rewards and employee creative performance: Moderating effects of creative self-efficacy, reward importance, and locus of control. Journal of Organizational Behavior, 36(1), 59-74.

Manolopoulos, D. (2006). What motivates R\&D professionals? Evidence from decentralized laboratories in Greece. The International Journal of Human Resource Management, 17(4), 616-647.

Montag, T., Maertz, C. P., \& Baer, M. (2012). A critical analysis of the workplace creativity criterion space. Journal of Management, 38(4), 1362-1386.

Mumford, M. D., \& Gustafson, S. B. (1988). Creativity syndrome: Integration, application, and innovation. Psychological Bulletin, 103(1), 27.

Oldham, G. R., \& Cummings, A. (1996). Employee creativity: Personal and contextual factors at work. Academy of management journal, 39(3), 607-634.

Podsakoff, P. M., MacKenzie, S. B., Lee, J. Y., \& Podsakoff, N. P. (2003). Common method biases in behavioral research: A critical review of the literature and recommended remedies. Journal of Applied Psychology, 88(5), 879.

Pretty, G. H., \& Seligman, C. (1984). Affect and the overjustification effect. Journal of Personality and Social Psychology, 46(6), 1241-1253.

Putwain, D. W., \& Symes, W. (2011). Teachers' use of fear appeals in the Mathematics classroom: Worrying or motivating students?. British Journal 
of Educational Psychology, 81(3), 456-474.

Ryan, R. M., \& Deci, E. L. (2000). Intrinsic and extrinsic motivations: Classic definitions and new directions. Contemporary Educational Psychology, 25(1), 54-67.

Scott, S. G., \& Bruce, R. A. (1994). Determinants of innovative behavior: A path model of individual innovation in the workplace. Academy of Management Journal, 37(3), 580-607.

Shalley, C. E., \& Gilson, L. L. (2004). What leaders need to know: A review of social and contextual factors that can foster or hinder creativity. The Leadership Quarterly, 15(1), 33-53.

Shalley, C. E., \& Perry-Smith, J. E. (2001). Effects of social-psychological factors on creative performance: The role of informational and controlling expected evaluation and modeling experience. Organizational Behavior and Human Decision Processes, 84, 1-22.

Tierney, P., \& Farmer, S. M. (2004). The Pygmalion process and employee creativity. Journal of Management, 30(3), 413-432.

Tierney, P., Farmer, S. M., \& Graen, G. B. (1999). An examination of leadership and employee creativity: The relevance of traits and relationships. Personnel Psychology, 52(3), 591-620.

Van Dyne, L., Jehn, K. A., \& Cummings, A. (2002). Differential effects of strain on two forms of work performance: Individual employee sales and creativity. Journal of Organizational Behavior, 23(1), 57-74.

Vroom, V. H. (1964). Work and motivation. Oxford, England: Wiley.

West, M. A., \& Farr, J. L. (1990). Innovation and creativity at work: Psychological and Organizational Strategjes. NY: John Wiley \& Sons, 265-267.

Woodman, R. W., Sawyer, J. E., \& Griffin, R. W. (1993).
Toward a theory of organizational creativity. Academy of Management Review, 18(2), 293-321.

Yang, H. C., Cho, H. Y., Kim, J. J., Eom, T. K., Kim, S. W., \& Youn, M. K. (2015). Effects of individuals, leader relationships, and groups on innovative work behaviors. International Journal of Industrial Distribution \& Business, 6(3), 19-25.

Yang, H. C., Cho, H. Y., \& Lee, W. D. (2015). Multi-dimensional emotional intelligence effects on intrinsic/extrinsic motivation and job satisfaction: Analysis using laborer perceived organizational support. The East Asian Journal of Business Management, 5(4), 13-18.

Yoon, H. J., Sung, S. Y., Choi, J. N., Lee, K., \& Kim, S. (2015). Tangible and intangible rewards and employee creativity: The mediating role of situational extrinsic motivation. Creativity Research Journal, 27(4), 383-393.

Zhang, X., \& Bartol, K. M. (2010). Linking empowering leadership and employee creativity: The influence of psychological empowerment, intrinsic motivation, and creative process engagement. Academy of Management Journal, 53(1), 107-128.

Zhou, J. (2003). When the presence of creative coworkers is related to creativity: Role of supervisor close monitoring, developmental feedback, and creative personality. Journal of Applied Psychology, 88, 413-422.

Zhou, J., \& George, J. M. (2001). When job dissatisfaction leads to creativity: Encouraging the expression of voice. Academy of Management Journal, 44(4), 682-696.

Zhu, Y. Q., Gardner, D. G., \& Chen, H. G. (2018). Relationships between work team climate, individual motivation, and creativity. Journal of Management, 44(5), 2094-2115. 
부 록

<Table 5> 연구에 사용된 설문 문항

\begin{tabular}{|c|c|}
\hline 변수 & 측정문항 \\
\hline 내재적 동기 & $\begin{array}{l}\text { 내가 매일 일하러 가는 이유는 } \\
\text { 1. 직무 자체를 즐기기 때문이다. } \\
\text { 2. 직무가 재미있기 때문이다. } \\
\text { 3. 직무가 매력적이라고 생각하기 때문이다. } \\
\text { 4. 일하러 가는 것을 즐기기 때문이다. }\end{array}$ \\
\hline 외재적 동기 & $\begin{array}{l}\text { 내가 매일 일하러 가는 이유는 } \\
\text { 5. 급여 때문이다. } \\
\text { 6. 승진기회 때문이다. } \\
\text { 7. 보너스 때문이다. } \\
\text { 8. 직업 보장(안정성) 때문이다. }\end{array}$ \\
\hline 유형의 보상 & $\begin{array}{l}\text { 9. 내가 내 직무를 창의적인 방식으로 수행한다면, 추가적인 재정적 인센티브를 받는다. } \\
\text { 10. 내가 창의적인 아이디어를 제안하는 것은 이 회사에서의 나의 수입에 긍정적인 영향을 미친다. } \\
\text { 11. 우리 회사는 직원들이 창의적으로 일할 때 상당한 보너스를 제공한다. } \\
\text { 12. 이 회사에서 창의적인 성과는 승진에 긍정적 영향을 미친다. }\end{array}$ \\
\hline 무형의 보상 & $\begin{array}{l}\text { 13. 내가 혁신적인 아이디어를 제공하면 나의 동료들은 나를 인정하고 격려한다. } \\
\text { 14. 내가 창의적인 아이디어를 많이 제안할수록 상사나 동료는 내게 더 긍정적인 태도를 보인다. } \\
\text { 15. 내가 창의적으로 직무를 수행하면 나는 회사로부터 긍정적인 피드백을 받는다. }\end{array}$ \\
\hline 창의성 & $\begin{array}{l}\text { 16. 나는 목표 달성을 위해 새로운 방식을 제안한다. } \\
\text { 17. 나는 성과 향상을 위해 새롭거나 실질적인 아이디어 등을 탐색한다. } \\
\text { 18. 나는 새로운 기술, 프로세스(공정), 기법, 제품 아이디어 등을 탐색한다. } \\
\text { 19. 나는 품질 향상을 위해 새로운 방식을 제안한다. } \\
\text { 20. 나는 창의적 아이디어를 잘 고안해낸다. } \\
\text { 21. 나는 위험을 감수하는 것이 두렵지 않다. } \\
\text { 22. 나는 내 아이디어를 다른 사람들에게 전파하고 옹호할 수 있다. } \\
\text { 23. 나는 직무에서 기회가 주어질 경우 창의성을 발휘할 수 있다. } \\
\text { 24. 나는 새로운 아이디어를 실행하기 위해 적절한 계획과 일정을 짠다. } \\
\text { 25. 나는 새롭고 혁신적인 아이디어가 자주 떠오른다. } \\
\text { 26. 나는 문제 해결을 위해 창의적인 솔루션(해법)을 고안해낸다. } \\
\text { 27. 나는 문제 해결을 위해 신선한 접근법을 자주 취한다. } \\
\text { 28. 나는 업무 수행을 위해 새로운 방식을 제안한다. }\end{array}$ \\
\hline
\end{tabular}

